\title{
Influence and Countermeasure of micro blog on College Students' Ideological and Political Education
}

\author{
Tu Liyan \\ Inner Mongolia University for the Nationalities, Tongliao, Inner Mongolia, 028000, China;
}

Keywords: micro blog; Ideological and Political Education; Measures

\begin{abstract}
As the platform of new information dissemination, the micro blog has the characteristics of instant and interactive, which is favored by the young people, especially the students, and has influenced the outlook on life and values of college students. The full use of micro blog to carry out ideological and political education for college students is an important measure to improve the effectiveness of Ideological and political education for college students. This paper analyzes the opportunities and challenges of the ideological and political education for college students, and puts forward some feasible measures to find the problems.
\end{abstract}

\section{Introduction}

The ideological education of college students is one of the most important works in the university management, and can carry out the ideological education work effectively to the University's survival and development. The emergence and the rise of the micro blog marks the arrival of the era of micro culture as a simple exchange platform, micro blog is also an important carrier of ideological dissemination. Because it has the characteristics of convenient, interactive and strong, etc., the micro blog is welcomed by many people [1]. In micro blog users, college students is a group that cannot be ignored, is the main force of using Twitter. Therefore, we should attach great importance to micro blogging in College Ideological and political education, and the role and influence of, on how to strengthen the micro blogging platform for college students of Ideological and political education becomes a problem that is worth to discuss [2].

This study first elaborated the meaning and the characteristic of the micro blogging, and in view of the problems existing in the current ideological and political education work, and further analyzed the influence of micro blog on the ideological and political education of university students, and formulated the corresponding suggestions and measures, and provides a way to improve the effect of ideological and political education.

\section{The connotation of micro blog culture}

Concept of micro blog. Micro blog is information dissemination platform based on user relationship. Users can set up personal community through the Internet, so as to share information in the form of text, pictures and so on. As a new application of network technology, it gets the promotion of major websites, and increasingly affects people's lifestyles. Micro blogging is the perfect combination of mobile media and the Internet, providing users with a social platform. For micro blogging users, this is not just a source of information, public discourse platform, but also a platform for entertainment and entertainment [3]. Survey report shows that the use of micro blogging reason mainly includes self display, record the mood, speech, about celebrities, growth of knowledge, to make friends, spend time etc, and the ratio as shown in Figure 1. Visible, micro blogging has penetrated into every aspect of college students' daily life, changing people's lives. 


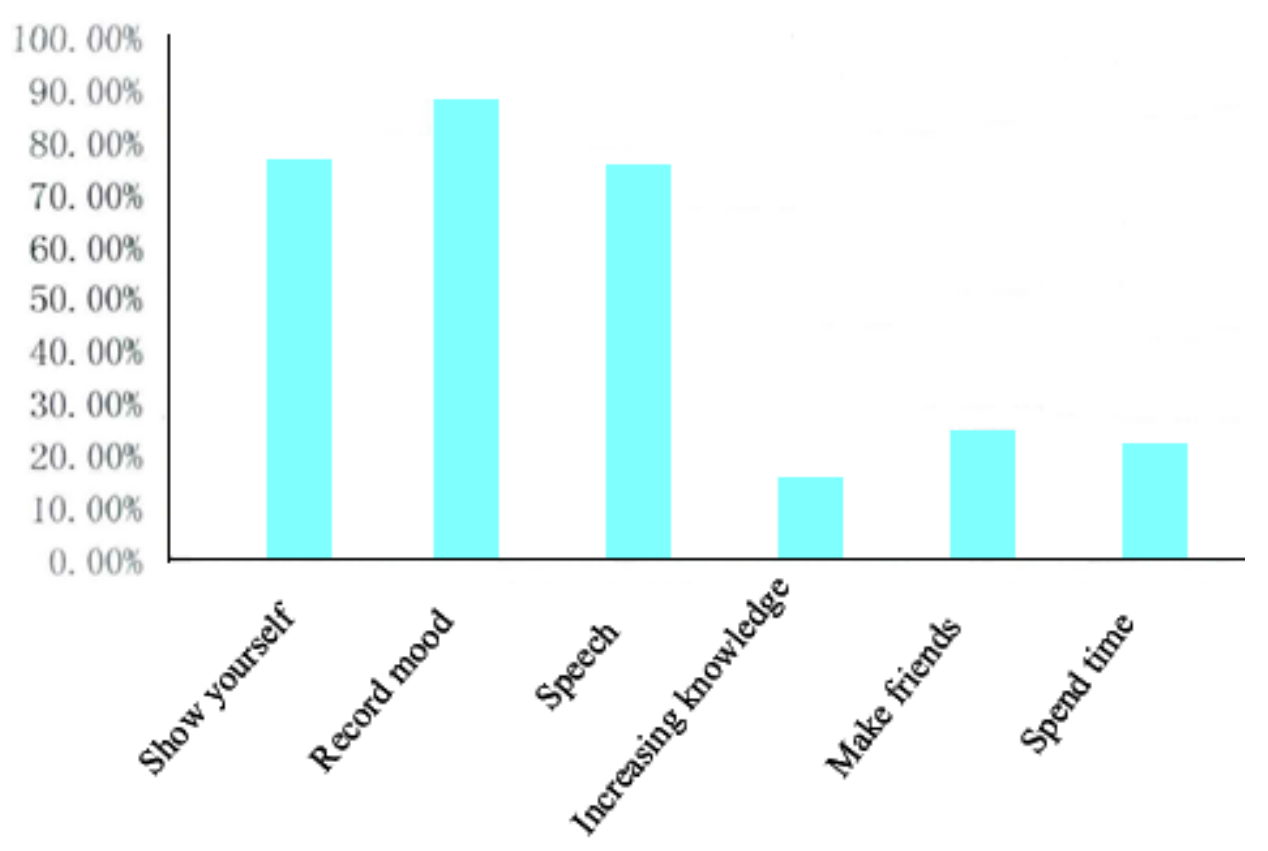

The main features of micro blog.

Fig.1 use micro blog motivation

\section{Spread fast}

The traditional mode of transmission is a "linear transmission", and the dissemination of micro Bo as the "fission type", its area and speed are unparalleled. The dissemination path of the micro blog can be a person released information [4][5], his fans can receive the information in time. You can also forward to others good micro blogging, so as to achieve the rapid spread of micro blogging. So, a micro blogging message through the user forwarded to the surrounding rapid spread, causing more and more people attention, communication as shown in Figure 2.

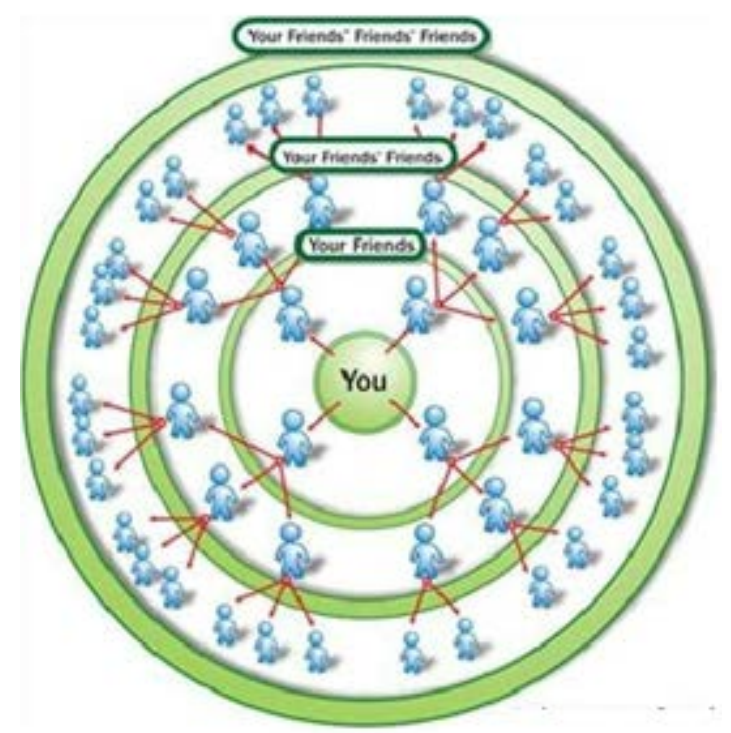

\section{Strong interaction}

Fig.2 transfer mode of micro blogging

Users can phone and other instant messaging tools landing micro blogging. 140 word limit micro blogging objectively greatly improves the micro blogging interaction, which has one of the characteristics of interpersonal communication, but it also can be "one to many" communication. Micro blogging users can not only publish information anytime, anywhere, while others focus on their own interest, which receive timely release of information as well as comments and express their feelings, to achieve the purpose of communication. Due to limitations of words, the publisher and interested parties tweets can timely respond to each other's comments, which achieved the goal 
to better communication. Students' debris into the information facilitated, making micro blogging interactive enhancements.

\section{Influence of micro blog on College Students' Ideological and Political Education}

\section{Positive impact}

1. Open up a new way for ideological and political education in Colleges and universities.

In the traditional ideological and political education, it is difficult to get the ideal effect through the way of classroom teaching. The micro blog provides a new communication channel for the teachers and students. Micro blog has the merits of the immediate release, free communication, subject to ideological and political education and college students welcome, making communication between teachers and students is not disturbed by the space constraints and other factors, provide new ways and methods for ideological and political education of college students.

2. Strengthen the effectiveness of Ideological and Political Education

Micro blog as a very appealing tool for the exchange of information, can in the form of text, pictures, graphics, sound, and display its ultra strong charm and attraction of Ideological and political education in Colleges and universities and educated attention, improve the everyone to participate in the micro blog initiative and enthusiasm. At the same time, between the teachers and students can also take advantage of the openness of micro blog characteristics, instantly reveal their true ideas, and exchange, share the views of others. Ideological and political education in Colleges and universities can through the micro blog concern or follow the educated micro blog, real-time grasp the psychological state of college students and demand and according to the level of knowledge of the individual and the ability to accept and develop educational programs, teach students in accordance of their aptitude. Only in this way can we mobilize the enthusiasm, initiative and creativity of the students to enhance the effectiveness of the ideological and political education.

3. It is benefit for college students to carry out ideological exchange

Micro blog provides a stage for college students to communicate with each other and become a tool for college students to pursue fashion and release pressure. Some students will be influenced by the factors such as study, love and interpersonal relationship, etc. it will have a bad effect on the psychology. Through participation in micro blog, the virtual world of social interaction, you can expand your social circle, to ease the psychological pressure of college students.

\section{Negative influence}

1. Shaken the mainstream consciousness of College Students

The spread of different cultures, some vulgar culture will enter the idea of college students.. College students have not yet entered society, world outlook, outlook on life and values are preliminarily formed, strong curiosity, the ability to distinguish between right and wrong, very easy by some false information to mislead, let students on social understanding deviation, causing huge obstacles to the dissemination and promotion of the mainstream ideology, shake the educated the mainstream consciousness.

2. Made a lot of garbage culture

The micro blog provides a chance for users to express themselves, and everyone is the producer and recipient of information. Use the phone and other communication tools can anytime, anywhere will own the state, mood released to the micro blog, others can also comment and forwarding it. Among the various kinds of information, some are not real, slander others, so there is a lot of garbage culture.

3. Indulge micro blog is not conducive to college students physical and mental health

Some students are obsessed with micro blog, micro blog formed dependence, are often unable to extricate themselves, addicted, frequent released micro blog, frequent refresh the page to see the latest micro blog, serious impact on the personal life and the efficiency of the classroom. Also due to the limitations of the virtual network let students exchange of real world blurred. It is difficult to distinguish between real and unreal world, reduce the students in the real world communication ability, brings new challenge to the ideological and political education in Colleges and universities. 


\section{The measures of improving the ideological and political education of College Students under the micro blog culture}

\section{Strengthen the supervision of micro blog}

The rapid development of micro blog, there is no match for the supervision and management mechanism, the lack of the corresponding legal system specification. The random and the openness of the micro blog bring us many conveniences, but also bring many bad effects. Without a strong legal supervision, rampant micro blog false information, network hype and irrational emotions and behavior, to society caused negative effects. Therefore, the government should establish an effective monitoring mechanism.

2. Adhere to the principle of combining traditional teaching methods and network technology

Over the years, the traditional ideological education with a purpose, planned way of teaching guide college students to establish the correct values, face to face communication between teachers and students, and enhance the college students' trust of teachers, and promote the education work smoothly. At the same time, we should also clearly see the adverse effects brought by the traditional ideological education in the face of new media technology, actively take the initiative to occupy the position of network ideological and political education in Colleges and universities, to comprehensively strengthen the construction of campus network, the network has become the allround development of an important means of Ideological and political education in Colleges and universities.

Twitter makes ideological and political education in Colleges and universities have rich teaching resources, expanding the knowledge content and break through the limit of time and space, between teachers and students can communicate anytime and anywhere. However, in micro blog spam also on College Students' thoughts and behavior misleading, increased the difficulty of the ideological and Political Education work. Will the traditional way of Ideological and political education and new media technology combined for the combination, take the essence to its dregs, methods and ways to improve the ideological and political education, and promoting the smooth development of Ideological and political education.

3. Establish the school micro blog platform, and create a new carrier of Ideological and political education work

Colleges and universities should establish the micro blog platform, give full play to the influence of micro blog in college students, and improve their ideological level. At present, some colleges and universities have not realized the great influence of the micro blog on the ideological and political education of college students, and have not explored the effective way of using the micro blog to carry out ideological and political education. For colleges and universities, the creation of the school should not only be the school micro blog timely, reasonable, scientific, and to maintain and run good this platform. By constructing a school official micro blogging platform, core values, the mainstream ideology and into the micro blogging, using novel topic and healthy content will be effective integration of Ideological and political education of college students and micro blogging, the micro Bo bring challenges into opportunities, use micro blogging platform for college students of Ideological and political education, give full play to the education function of micro blogging, improve the effectiveness of the work of Ideological and political education in Colleges and universities.

\section{Conclusion}

The rapid development of micro blog and popularization of great changes of college students learning, life and ideas, but also to the ideological and political education work in Colleges and universities development has brought new opportunities and challenges. How to combine the micro blog with the ideological and political education work, give full play to its unique advantages, and more effective development of Ideological and political education for college students become a new topic in front of colleges and universities. This article from the micro blog and ideological and political education in the relevant theoretical content, in-depth analysis of the micro blog to college 
ideological and political education work brings opportunities and challenges. In view of the problems existing in the ideological and political education in Colleges and universities, the Countermeasures for strengthening the ideological and political education of the University's micro blog are proposed.

\section{References}

[1] Terence Copley, Indoctrination, Education and God: The Struggle for the Mind, London: Ashford Colour Press, 2005.

[2] Sam Kaplan, Nuriye's Dilemma: Turkish Lessons of Democracy and the Gendered State. American Ethnologist, 2003, 30(3):401-417.

[3] Stephen De Wize, The Family and Political Justice: The Case for Political Liberalisms, Journal of Ethics, 2000, 4(3):257-281.

[4] Clark A. Miller, Interrogating the Civic Epistemology of American Democracy: Stability and Instability in the 2000 US Presidential Ehction, Social Studies of Science, 2004, 34(4): 501-530.

[5] Joanildo A. Burity, Laurence Hallewell, Reform of the State and the New Discourse on Social Policy in Brazil. Latin American Perspectives, 2006, 33(3). 